\title{
Penerapan Metode Prototype Pada Perancangan Sistem Informasi Penggajian Karyawan (Persis Gawan) Berbasis Web
}

\author{
Eka Wulansari Fridayanthie ${ }^{1}$, Haryanto ${ }^{2}$, Tsamarah Tsabitah ${ }^{3}$ \\ 1,2,3 Universitas Bina Sarana Informatika \\ 1e-mail: eka.ewf@bsi.ac.id \\ 2e-mail: haryanto.hyt@bsi.ac.id \\ 3e-mail: tsamar12182708@bsi.ac.id
}

\begin{abstract}
Abstrak - Pada penelitian ini membahas mengenai penerapan metode prototype pada perancangan sebuah sistem informasi penggajian karyawan berbasis website. Adapun study kasus yang digunakan adalah PT Bina Angkasa, yaitu perusahaan yang bergerak dibidang pengiriman kargo atau barang melalui perjalanan darat dan laut. Sistem penggajian yang saat ini digunakan pada PT Bina Angkasa masih menggunakan sistem manual dimana semua proses penggajian dicatat dimedia kertas sehingga sangat memungkinkan terjadinya kesalahan data dan kerangkapan data sehingga bisa mengakibatkan terhambatnya proses penerimaan gaji kepada karyawan. Penulis menggunakan metode deskriptif dalam penelitian yang dilakukan saat ini. Metode pengembangan yang dipilih oleh penulis adalah metode prototype. Karyawan melakukan absensi secara otomatis pada sistem absensi, data absen yang tersimpan pada database inilah yang akan diproses oleh admin untuk menghitung gaji karyawan. Selanjutanya admin akan mencetak slip gaji dan membuat laporan penggajian. Dengan demikian sistem informasi penggajian karyawan ini akan efektif dan efisien. Berdasarkan hasil penelitian yang dilakukan, sistem ini telah dirancanga dengan sangat baik dan sesuai dengan yang direncanakan sehingga prototype ini dapat digunakan sebagai acuan untuk melanjutkan pengembangan sistem yang dibuat. Hasil rancangan dari sistem ini dapat digunakan sebagai dokumentasi bagi pihak PT Bina Angkasa dan dapat dijadikan sebagai sebuah literatur untuk mengembangkan sistem penggajian karyawan.
\end{abstract}

Kata Kunci: Sistem Informasi, Penggajian, Metode protoype

\begin{abstract}
This study discusses the application of the prototype method in the design of an employee recruitment information system based on a website. In this study, the case study used is PT Bina Angkasa, a company engaged in the delivery of cargo or goods via land and sea travel. This study adapts to the business processes that run at PT Bina Angkasa, as well as according to the current system activities that are currently taking place. The author uses a descriptive method in the current research. The development method chosen by the author is the prototype method. The application of the prototype method greatly facilitates research design with the aim of describing and explaining the condition of the object and also making it easier to design the system. The objective of this research is to produce an effective and efficient employee payroll information system design. Based on the results of the research carried out, this system has been designed very well and in accordance with what was planned so that this prototype can be used as a reference to continue the development of the system made. The design results of this system can be used as documentation for PT Bina Angkasa and can be used as a literature to develop employee reward systems.
\end{abstract}

Keyword : Information System, Payroll, Protoype Method

\section{PENDAHULUAN}

Pada Saat ini peran teknologi sangatlah membantu dalam setiap aktifitas yang dilakukan oleh manusia dapat dibuktikan dari hadirnya komputer yang dapat dipergunakan untuk menukaran data, melaksanakan pengetikan dokumen dan pengaksesan internet membuatnya semakin banyak digunakan karena kemudahan dalam mengaplikasikannya. (Hasni, 2017) Selain itu dengan adanya teknologi informasi yang dapat memberikan kemudahan dalam memenuhi kebutuhan perusahaan atau organisasi dengan efisien, akurat, relevan dan tepat waktu sehingga kemudahan menggunakan komputer juga membuat pekerjaan dapat dikerjakan dalam waktu yang tidak terlalu lama.

Setiap perusahaan pastilah memiliki karyawan yang bekerja untuk memajukan perusahaan, dari berbagai bidang, setiap perusahaan mempunyai sistem yang berbeda-beda mulai dari sistem penerimaan karyawan, sistem pengabsenan karyawan, sampai 
dengan sistem penggajian karyawan. (Jayanti, 2018) Karwayan menerima gaji setiap bulannya sesuai dengan standar gaji yang ditetapkan oleh perusahaan tersebut setelah karyawan melakukan kewajibannya dalam pekerjaan yang telah diperintahkan kepadanya. Sistem Penggajian dalam perusahaan merupakan aspek penting karena akan berpengaruh terhadap laporan keuangan perusahaan tersebut.

Menurut Mulyadi dalam (Ariani, 2019)(Nuris \& Ariani, 2019), "Penggajian adalah pembayaran atas jasa yang dilakukan oleh karyawan yang mempunyai jenjang jabatan yang pada umumnya dibayarkan per bulan".

PT. Bina Angkasa merupakan perusahaan yang bergerak dibidang pengiriman kargo atau barang melalui perjalanan darat dan laut. Dalam PT Bina Angkasa terdapat beberapa karyawan yang terdiri dari berbagai divisi yang bertugas dalam bidangnya masing - masing.Dalam sistem penggajian pada PT. Bina Angkasa masih menggunakan metode manual yaitu menggunakan berkas - berkas yang memungkinkan terjadinya kehilangan atau terselip jika tidak teliti dalam menyimpan atau mengelola berkas yang diperlukan.

\section{METODOLOGI PENELITIAN}

\section{A. Metode Deskriptif}

Penelitian ini dilaksanakan sesuai dengan proses bisnis yang berjalan pada PT. Bina Angkasa dan juga berkaitan dengan kegiatan yang dilaksanakan penerimaan karyawan yang berjalan. Penelitian ini menggunakan metode deskriptif yang menjelaskan sebagai berikut:

Metode deskriptif adalah metode untuk memeriksa keadaan kelompok manusia saat ini, subjek, kondisi, sistem pemikiran, atau kategori peristiwa. (Minarsih, 2016) Tujuan dari penelitian deskriptif ini adalah untuk mendeskripsikan atau melukiskan hubungan kejadian yang dialami secara sistematis.

\section{B. Metode Prototype}

Sedangkan untuk Perancangan sistemnya penulis menggunakan metode prototyping .Prototyping merupakan proses yang digunakan untuk membantu pengembangan perangkat lunak dalam membentuk model perangkat lunak (Syarif, 2018). Prototype ini adalah versi awal dari sebuah tahapan sistem perangkat lunak yang digunakan untuk mempresentasikan gambaran dari ide, mengeksperimenkan sebuah rancangan, mencari masalah yang ada sebanyak mungkin serta mencari solusi terhadap penyelesaian masalah tersebut. Model prototype yang dipergunakan oleh sistem akan mengijinkan pengguna mengetahui seperti apa tahapan sistem yang dibuat sehingga sistem dapat mampu beroperasi secara baik. Metode prototype yang diterapkan pada penelitian ini dimaksudkan agar mendapatkan representasi dari pemodelan aplikasi akan dibuat. Awal mula dari Rancangan aplikasi berbentuk mockup lalu akan dievaluasi oleh pengguna. Setelah mockup dievaluasi pengguna tahap berikutnya mockup akan dijadikan bahan rujukan bagi pengembang software untuk membangun aplikasi.

Beberapa keuntungan menggunakan Metode prototype yaitu:

1. Prototype akan membuat pengguna terlibat langsung dalam proses analisa dan desain.

2. Prototype mampu memahami segala kebutuhan secara nyata bukan secara abstrak

3. Prototype dapat dipergunakan agar memperjelas SDLC

Selain keuntungan menggunakan Prototype juga akan penulis jelaskan mengenai tahapan dalam prototype (Ni Luh Ade Mita Rahayu Dewi, 2021), yaitu:

1. Tahap Pengumpulan Kebutuhan

Pengembang dan klien akan sama-sama mendefinisikan Format sotfware dan mengidentifikasi kebutuhan dari sistem yang dibangun. Dalam tahap akan didefinisikan para pengguna sistem seperti admin dan user yang akan terlibat dalam sistem.

2. Tahap Prototyping

Tahap ini yaitu pelanggan atau klien akan menjelaskan keinginannya kepada perancang sistem untuk membuat perancangan sementara meliputi Fitur menu yang cepat dan mudah, Tampilan input dan output.

3. Tahap Evaluasi Prototyping

Pada tahapan ini klien akan dilakukan pengecekan terhadap prototype yang sudah dibangun dengan maksud memastikan sistem yang dirancang sudah sesuai dengan tujuan dan keperluan dari klien. Apabila prototype yang dibangun belum sesuai dengan keinginan klien maka akan dilakukan koreksi serta perbaikan dengan kembali. Tahap ini akan menyempurnakan tampilan input dan output yang belum sesuai ataupun perlu penambahan fitur baru.

4. Tahap Mengkodekan Sistem

Prototype yang telah disetujui pada tahap sebelumnya oleh klien akan di mulai proses dibuatkan dalam bentuk kode atau koding pada tahapan ini, dengan cara menterjemahkannya ke dalam bahasa pemrogramann yang digunakan. Bahasa pemrograman berbasis web php. Database menggunakan mysql. 
5. Tahap Pengujian Sistem

Sistem yang telah diubah ke dalam bahasa pemrograman dan apabila telah menjadi sebuah perangkat lunak maka akan diuji terlebih dahulu untuk menentukan apakah perangkat lunak tesebut telah layak digunakan atau belum. Pengujian yang dilakukan mempunyai tujuan untuk memastikan meminimalisir kesalahan yang ada biasanya pengujian melalui Black Box, White box, Pengujian arsitektur, Basis path atau yang lainnya.

6. Tahap Evaluasi Sistem

Pada tahap pengevaluasian ini klien melakukan evaluasi untuk memastikan apakah program atau sistem yang sudah dibangun sudah sesuai dengan keinginan atau belum. Apabila telah sesuai maka sistem sudah dapat digunakan. Tapi apabila dinyatakan belum sesuai maka pengembang harus kembali ket tahap sebelumnya untuk memperbaiki ketidakseuaian itu sesuai dengan keinginan si klien.

7. Tahap Menggunakan Sistem

Sistem yang dibangun dan berhasil melewati tahapan evaluasi sistem dengan baik maka sistem tersebut sudah dapat digunakan.

\section{HASIL DAN PEMBAHASAN}

Dalam penelitian ini dilakukan sesuai tahapan yang ada pada model prototype untuk mempermudah pembaca dalam memahami proses dari awal sampai sistem selesai dan implementasi dalam kehidupan.

1. Analisa Kebutuhan Perangkat Lunak

Pada tahap ini peneliti akan menganalisa kebutuhan apa saja yang diperlukan demi pembuatan sistem yang sesuai dengan keinginan.

Tahap Pengumpulan Kebutuhan

Dalam sistem penggajian ini terdapat karyawan dan admin atau yang kita sebut sebagai staff keuangan. Staff keuangan dan karyawan berinteraksi untuk menghasilkan sistem penggajian yang diinginkan serta memiliki ruang lingkup sistem yang berbeda beda sesuai dengan kebutuhan mereka dalam sistem tersebut. Seperti berikut : Kebutuhan Admin meliputi Mengelola data absen, membuat rekap absen, membuat slip gaji, membuat rekap gaji, membuat laporan gaji, kebutuhan karyawan, melakukan absen, ,melihat slip gaji. Sedangkan untuk kebutuhan sistem meliputi pengguna harus melakukan login terlebih dahulu pada saat membuka website dengan cara memasukan username beserta password agar privasi pengguna dapat terjaga keamanannya, sistem dapat melakukan proses absensi sesuai yang diinginkan pengguna, sistem dapat melakukan rekap absensi, sistem dapat membuat slip gaji, sistem dapat menampilkan absen sesuai permintaan pengguna, sistem dapat menampilkan slip gaji, sistem dapat melakukan pelaporan penggajian. (TM, 2016)

Sistem operasi yang umum digunakan seperti: Microsoft Windows atau Linux (Ubuntu, Fedora, dll).

(2) Aplikasi bundle web server seperti: Xampp, WampServer, php2triad yang terdiri dari beberapa komponen, diantaranya: Aplikasi Apache Server v2, Aplikasi PHP Server v5, Aplikasi MySQL Server v5, Aplikasi phpMyAdmin v3, Aplikasi Web Lihatr seperti Mozilla Firefox, Opera, Safari, Internet Explorer, Google Chrome. Sedangkan untuk client Sistem operasi yang umum digunakan seperti: Microsoft Windows atau Linux (Ubuntu, Fedora, dan lain-lain), dan Aplikasi web browser seperti Mozilla Firefox, Opera, Safari, Internet Explorer, Google Chrome.

\section{Desain}

Selanjutnya setelah mendalami kebutuhan apa yang diinginkan oleh pengguna, akan dilakukan perancangan atau biasa disebut design. Membuat rancangan perangkat lunak ini berguna untuk menggambarkan rancangan sebelum dilakukan pengkodingan program.

a. Rancangan Use Case

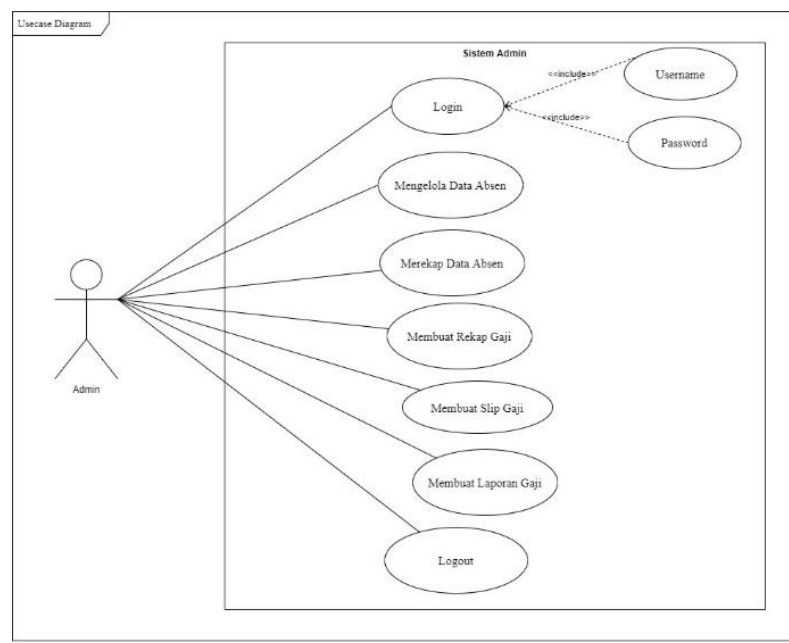

Gambar 1. Rancangan Use Case Menu Admin

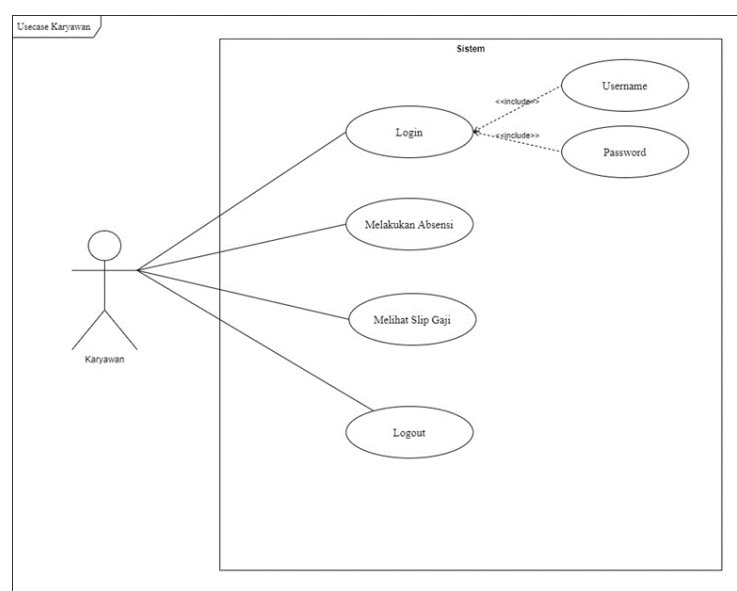

Gambar 2. Rancangan Use Case Menu Karyawan 
b. Rancangan Activity Diagram

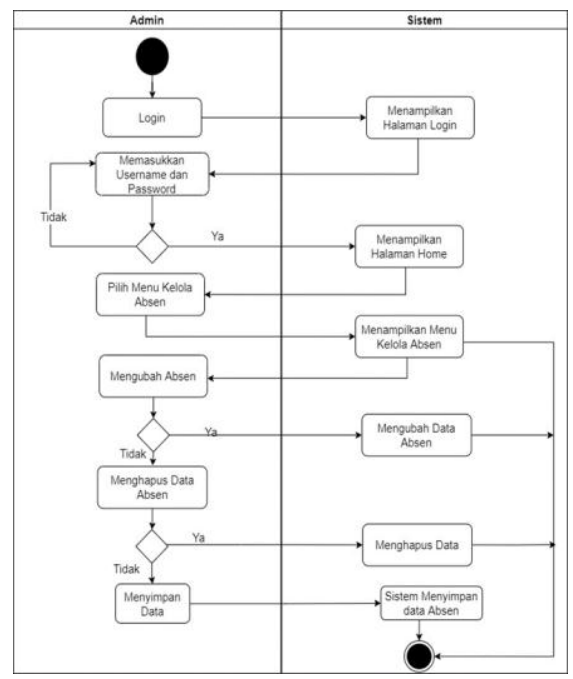

Gambar 3. Rancangan Activity Diagram Admin Mengelola Absen

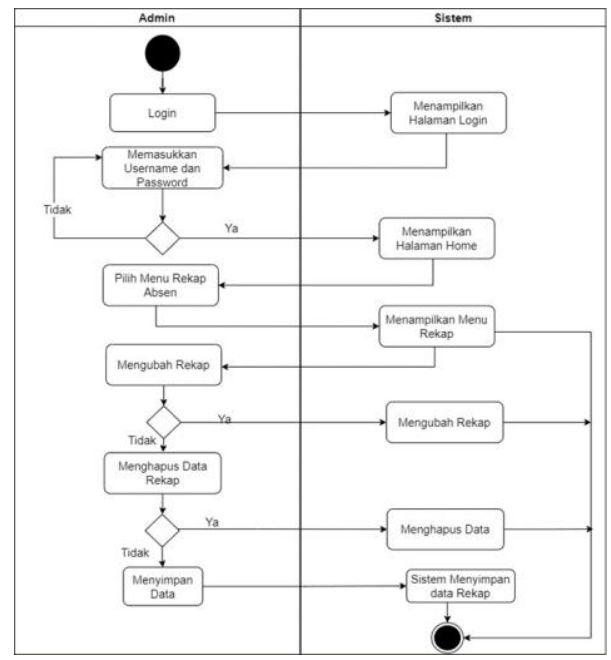

Gambar 4. Rancangan Activity Diagram Admin Merekap Absen

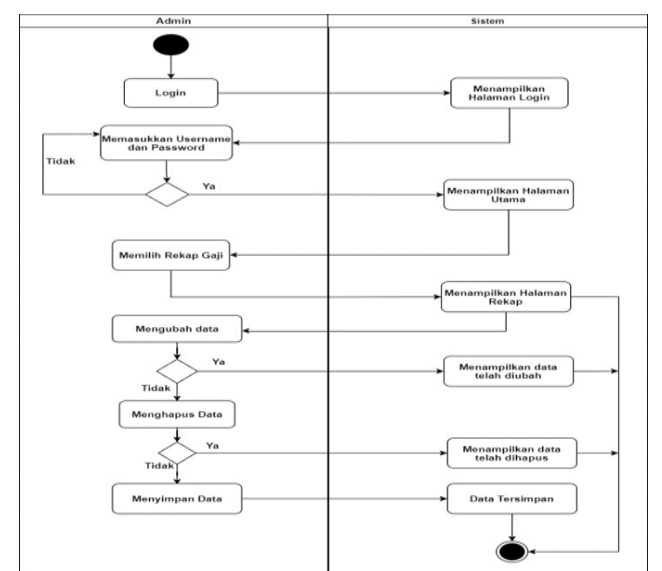

Gambar 5. Rancangan Activity Diagram Admin Merekap Gaji

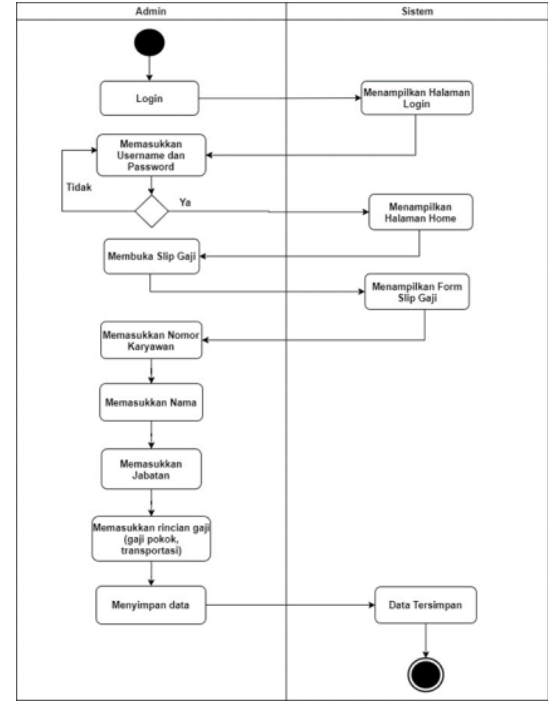

Gambar 6. Rancangan Activity Diagram Admin Membuat Slip Gaji

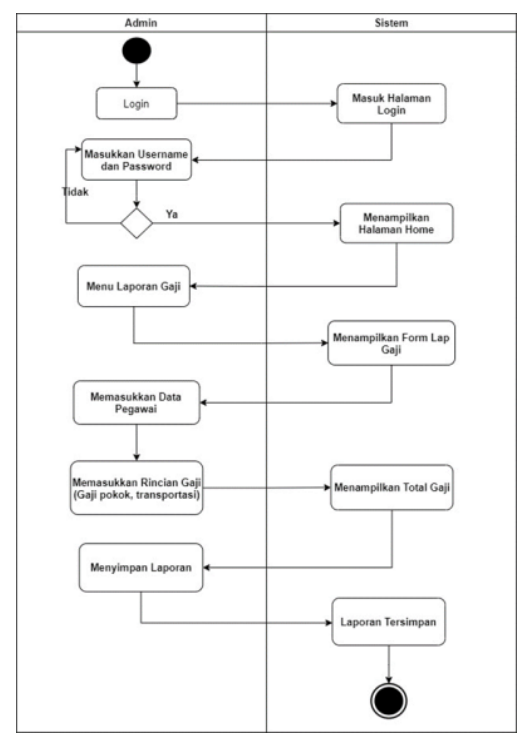

Gambar 7. Rancangan Activity Diagram Admin Membuat Laporan Gaji

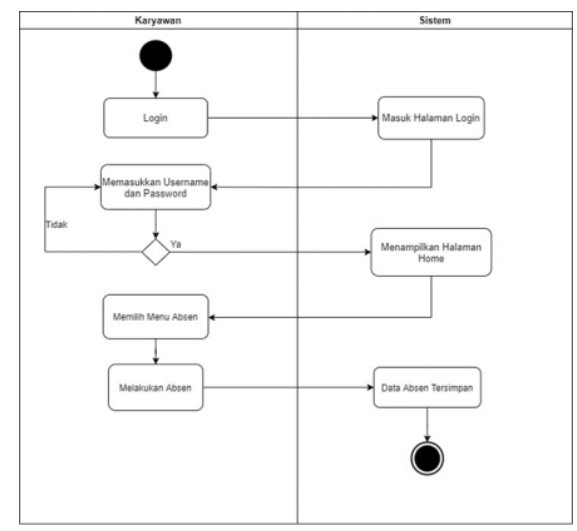

Gambar 8. Rancangan Activity Diagram Karyawan Melakukan Absen 


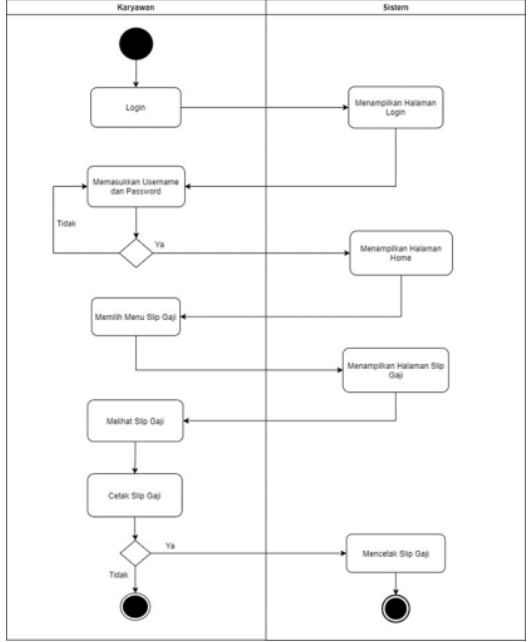

Gambar 9. Rancangan Activity Diagram Karyawan Melihat Slip Gaji

\section{c. ERD}

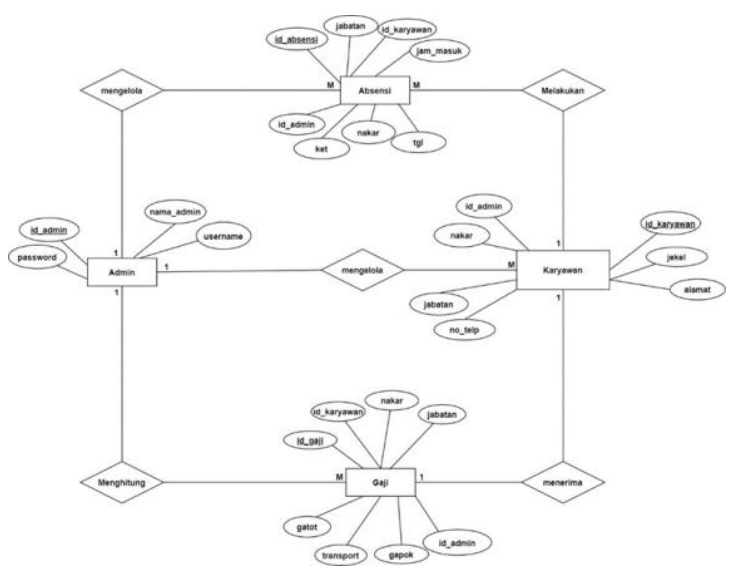

Gambar 10. Rancangan ERD

d. LRS

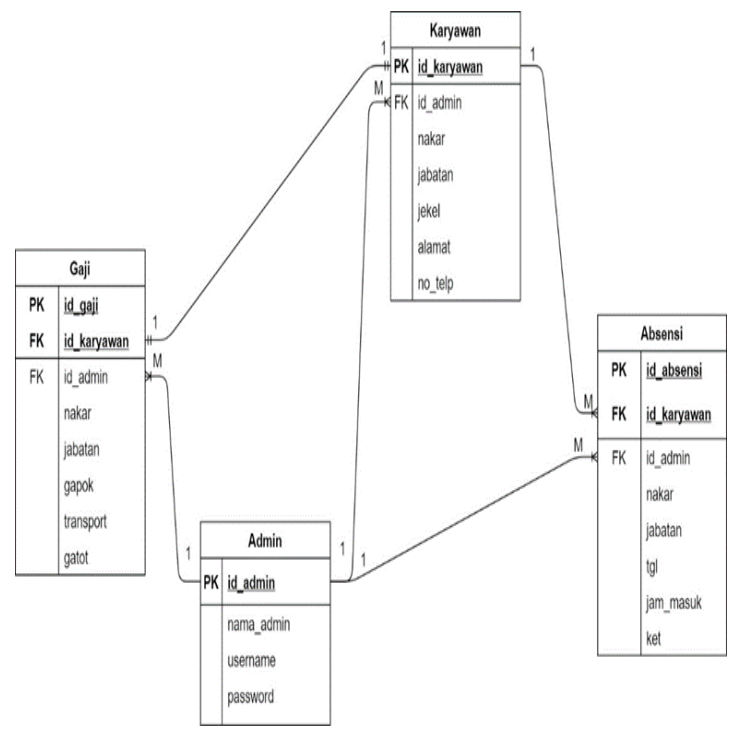

Gambar 10. Rancangan LRS e. Class Diagram

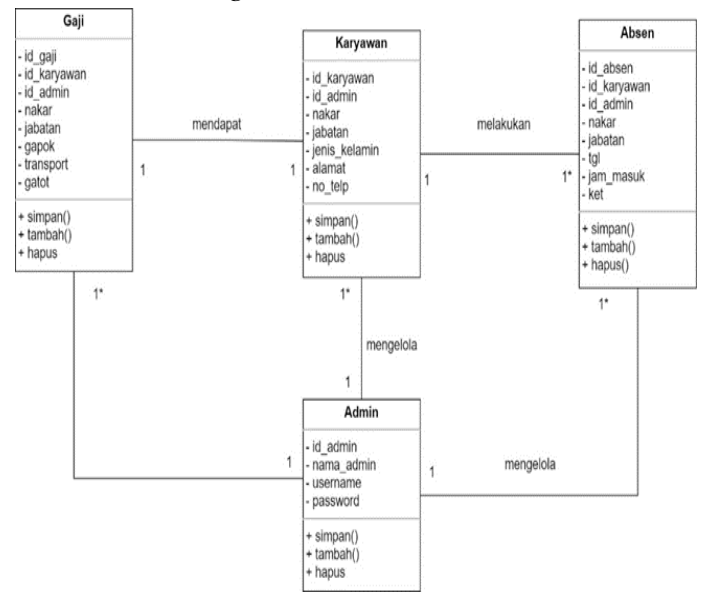

Gambar 11. Rancangan Class Diagram

f. Rancangan Sequence Diagram

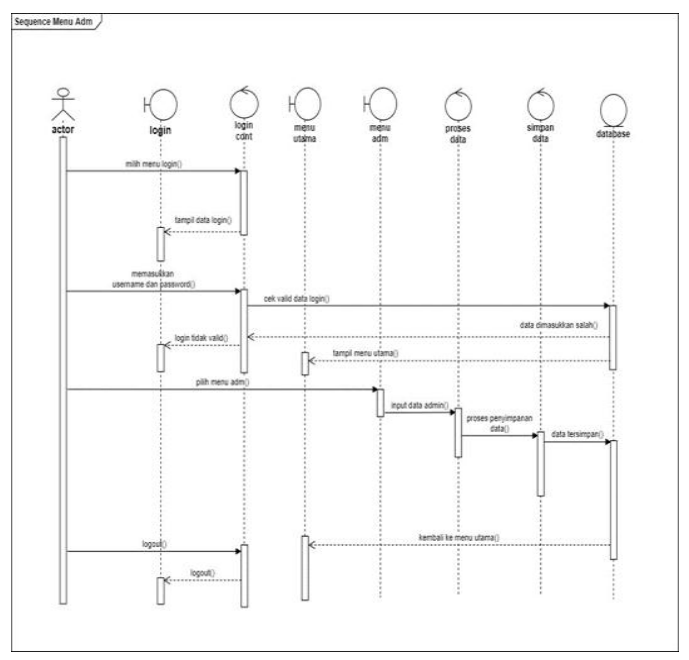

Gambar 11. Rancangan Sequence Diagram Menu Admin

3. Tahap Pengkodean (Pembuatan Kode Program)

Setelah ini dibuat kode program yang akan menghasilkan rancangan antarmuka

a. Rancangan Antarmuka Admin

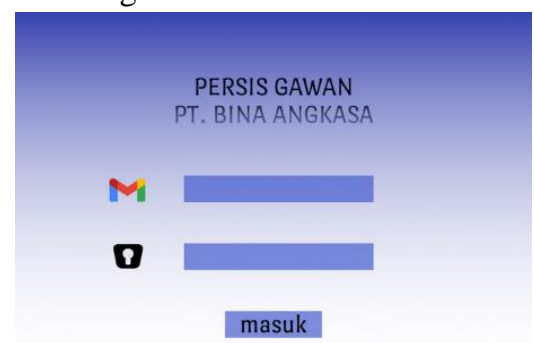

Gambar 12. Rancangan Antarmuka Admin Login 


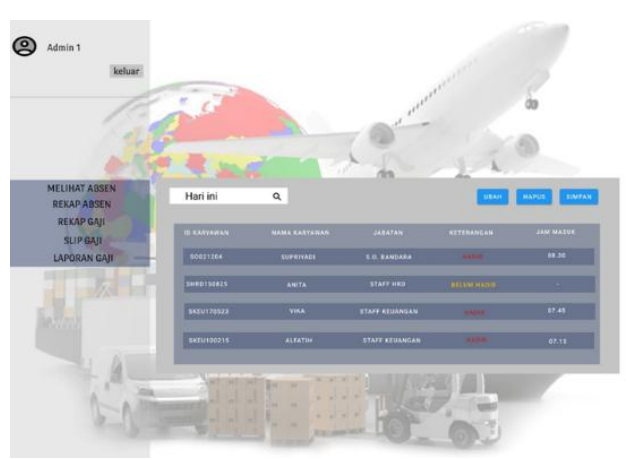

Gambar 13. Rancangan Antarmuka Kelola Absen

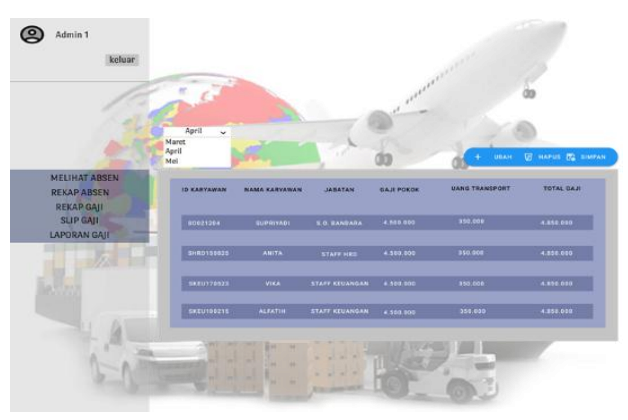

Gambar 14. Rancangan Antarmuka Admin Rekap Gaji

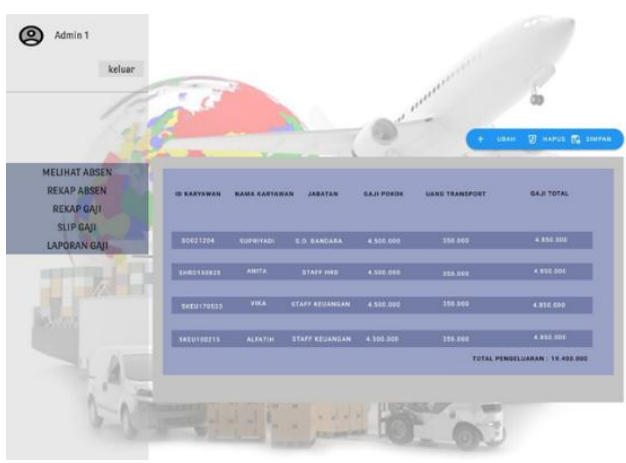

Gambar 15. Rancangan Antarmuka Admin Laporan Gaji

b. Rancangan Antarmuka Pengguna

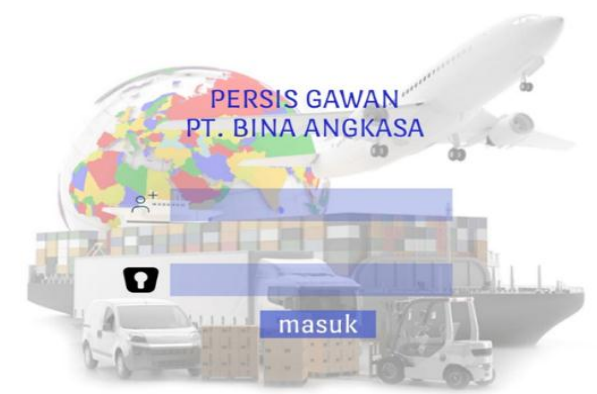

Gambar 16. Rancangan Antarmuka Login Karyawan

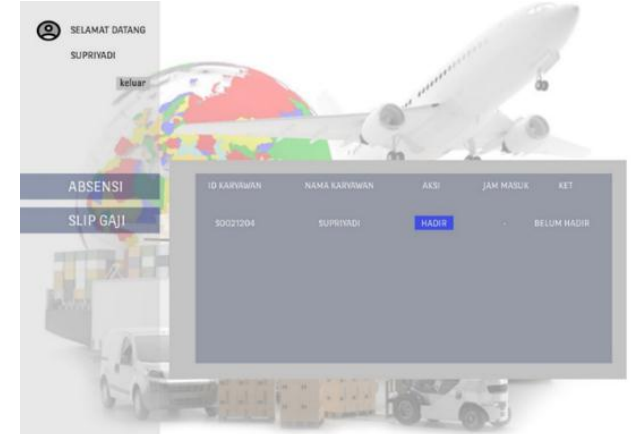

Gambar 17. Rancangan Antarmuka Absen Karyawan

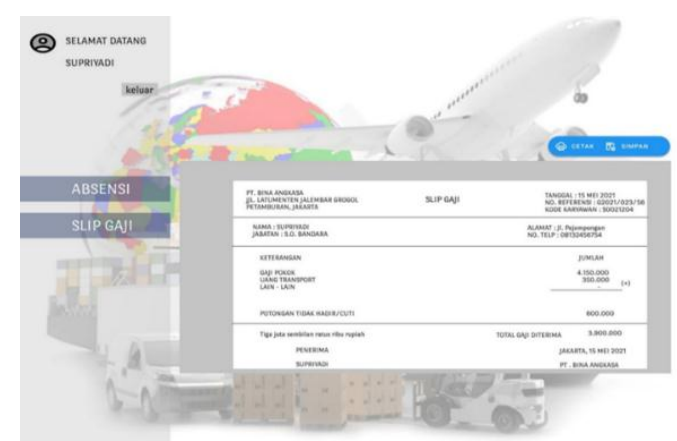

Gambar 18. Rancangan Antarmuka Slip Gaji Karyawan

4. Tahap Pengujian (Pengujian Program)

Setelah selesai melakukan pembuatan program yang menghasilkan rancangan muka selanjutnya dibuatkan pengujian yang dimana untuk mengetahui apakah program itu berhasil atau tidak

a. Pengujian Front End

Tabel 1. Pengujian Front End

\begin{tabular}{|c|c|c|c|c|}
\hline Partisipan & $\begin{array}{c}\text { Login } \\
\text { Karyawan }\end{array}$ & $\begin{array}{c}\text { Akses } \\
\text { Menu }\end{array}$ & $\begin{array}{c}\text { Melakukan } \\
\text { Absen }\end{array}$ & $\begin{array}{c}\text { Akses } \\
\text { Slip Gaji }\end{array}$ \\
\hline 1 & $\sqrt{ }$ & $\sqrt{ }$ & $\sqrt{ }$ & $\sqrt{ }$ \\
\hline 2 & $\sqrt{ }$ & $\sqrt{ }$ & $\sqrt{ }$ & $\sqrt{ }$ \\
\hline 3 & $\sqrt{ }$ & $\sqrt{ }$ & $\sqrt{ }$ & $\sqrt{ }$ \\
\hline 4 & $\sqrt{ }$ & $\sqrt{ }$ & $\sqrt{ }$ & $\sqrt{ }$ \\
\hline 5 & $\sqrt{ }$ & $\sqrt{ }$ & $\sqrt{ }$ & $\sqrt{ }$ \\
\hline Sukses & 5 & 5 & 5 & 5 \\
\hline $\begin{array}{c}\text { Nilai } \\
\text { Kesuksesan }\end{array}$ & $100 \%$ & $100 \%$ & $100 \%$ & $100 \%$ \\
\hline
\end{tabular}

b. Pengujian Back End

Tabel 2. Pengujian Back End

\begin{tabular}{|c|c|c|c|c|c|c|c|}
\hline Partisipan & $\begin{array}{c}\text { Login } \\
\text { Admin }\end{array}$ & $\begin{array}{c}\text { Akses } \\
\text { Menu }\end{array}$ & $\begin{array}{c}\text { Melihat } \\
\text { Absen }\end{array}$ & $\begin{array}{c}\text { Akses } \\
\text { Rekap } \\
\text { Absen }\end{array}$ & $\begin{array}{c}\text { Rekap } \\
\text { Gaji }\end{array}$ & $\begin{array}{c}\text { Slip } \\
\text { Gaji }\end{array}$ & $\begin{array}{c}\text { Laporan } \\
\text { Gaji }\end{array}$ \\
\hline 1 & $\sqrt{ }$ & $\sqrt{ }$ & $\sqrt{ }$ & $\sqrt{ }$ & $\sqrt{ }$ & $\sqrt{ }$ & $\sqrt{ }$ \\
\hline 2 & $\sqrt{ }$ & $\sqrt{ }$ & $\sqrt{ }$ & $\sqrt{ }$ & $\sqrt{ }$ & $\sqrt{ }$ & $\sqrt{ }$ \\
\hline Sukses & 2 & 2 & 2 & 2 & 2 & 2 & 2 \\
\hline $\begin{array}{c}\text { Nilai } \\
\text { Kesuksesan }\end{array}$ & $100 \%$ & $100 \%$ & $100 \%$ & $100 \%$ & $100 \%$ & $100 \%$ & $100 \%$ \\
\hline
\end{tabular}

\section{KESIMPULAN}

Berdasarkan hasil penelitian yang telah dibahas, maka dapat diambil disimpulkan bahwa perancangan sistem informasi penggajian karyawan 
yang diproses sesuai dengan tahapan-tahapan prototype dari rancangan yang digambarkan dengan pada Activty diagram, Usecase diagram, entity relationship diagram, konseptual database beserta rancangan interface. Desain program atau coding dengan menggunakan bahasa Aplikasi bundle web server, akan mebuat rancangan aplikasi penggajian yang lebih baik. Prototype atau hasil rancangan yang di buat, nantinya bisa dijadikan untuk acuan dalam pengembangan sistem ke tahap pengkodean atau dapat digunakan sebagai dokumentasi oleh pihak PT. Bina Angkasa. Perancangan yang telah di buat ini bisa diuji dan dikembangkan kembali agar sistem yang akan dibangun lebih baik lagi. Dengan adanya sistem informasi penggajian ini maka diharapkan perusahaan dapat melakukan penghitungan gaji dengan lebih efektif dan efisien sehingga meminimalisir kesalahan.

\section{REFERENSI}

Ariani, N. d. (2019). Sistem Informasi Seleksi Penerimaan Pegawai Dengan Metode Waterfall. Akademika, 13-17.

Hasni, I. d. (2017). Sistem Penggajian Karyawan Pada LKP Grace Education Center. jurnal una, 125-136.

Ichsan. (November 2013). Sistem Pendukung Keputusan Pemilihan Penerima Beasiswa Mahasiswa Kurang Mampu Pada STMIK BUDIDARMA Medan Menerapkan Metode Profile Matching. Kursor, 5(1), 2. Haettu 14. April 2016 osoitteesta http://pelita-

informatika.com/berkas/jurnal/1.\%20TM\% 20Syahru.pdf

Jayanti, M. D. (2018). Perancangan Sistem Informasi Manajemen Distribusi Gas Elpiji
Berbasis Web. Jurnal Khatulistiwa Informatika, 151-158.

Minarsih, A. F. (2016). Studi Deskriptif Pelatihan dan Pengembangan Sumberdaya Manusia Serta Penggunaan Metode Behavioral Event Interview Dalam Merekrut karyawan Baru. Journal of Management, 36.

Ni Luh Ade Mita Rahayu Dewi, R. S. (2021). Penerapan Metode Prototype dalam Perancangan Sistem Informasi Penerimaan Karyawan Berbasis Web Pada Berlian Agency. Majalah Ilmiah Teknologi Elektro, 147-152.

Syarif, W. N. (2018). Penerapan Metode Prototype Dalam Perancangan Sistem Informasi Penghitungan Volume dan Cost Penjualan Minuman Berbasis Website. Jurnal Sistem Informasi Musirawas, 97-105.

TM, E. W. (2016). Rancang Bangun Sistem Informasi Permintaan ATK Berbasis Intranet (Studi Kasus: Kejaksaan Negeri Rangkas Bitung). Jurnal Khatulistiwa Informatika, 152-154.

\section{PROFIL PENULIS}

Eka Wulansari Fridayanthie merupakan Dosen Aktif di Program Studi Sistem Informasi (D3) Universitas Bina Sarana Informatika, yang telah aktif mengajar sejak 2006 dengan beberapa mata kuliah yang telah diampunya.

Tsamarah Tsabitah merupakan mahasiswa aktif di Universitas Bina Sarana Informatika (UBSI). Saat ini sedang menempuh pendidikan D3 pada program studi Sistem Informasi 